\title{
Spontaneous Conception Following Laparoscopic Surgery in Women with Infertility at the Yaoundé Gyneco-Obstetric and Pediatric Hospital: A Cross- Sectional and Analytical Study
}

Marie Noelle Mokam ( $D$ marinomokam@yahoo.com )

Universite des Montagnes Faculté des Sciences de la Santé: Universite des Montagnes Faculte des

Sciences de la Sante

Cyrille Claude Noa Ndoua

Centre Hospitalier de Recherche et d'Application en Chirugie Endoscopique et Reproduction Humaine

Felicite Djuikwo

Université des Montagnes FSS: Universite des Montagnes Faculte des Sciences de la Sante

Arsène Brunelle Sandie

Jomo Kenyatta University of Agriculture and Technology

Samuel Ojong

University of Yaounde I: Universite de Yaounde I

Pascal Foumane

Hopital gyneco-obstetrique et pediatrique de Yaounde

Research article

Keywords: conception rate, Infertility, Laparoscopic surgery, Yaounde

Posted Date: October 30th, 2020

DOI: https://doi.org/10.21203/rs.3.rs-97770/v1

License: (c) (i) This work is licensed under a Creative Commons Attribution 4.0 International License.

Read Full License 


\title{
RESEARCH
}

\section{Spontaneous conception following laparoscopic surgery in women with infertility at the Yaoundé Gyneco-Obstetric and Pediatric Hospital: a cross-sectional and analytical study}

\author{
Marie Noelle Mokam Fopoussi ${ }^{1 *}$ \\ , Cyrille Claude Noa Ndoua ${ }^{2}$ \\ , Felicite Djuikwo ${ }^{3}$ \\ , Arsène Brunelle Sandie ${ }^{4}$ \\ , Samuel Ojong 5 \\ and Pascal Foumane ${ }^{6}$
}

\footnotetext{
${ }^{*}$ Correspondence: marinomokam@yahoo.com

${ }^{1}$ Faculty of Health Sciences,

Université des Montagnes,

Baganté, Cameroon

Full list of author information is

available at the end of the article
}

\begin{abstract}
Background: The infertility is a common health issue affecting many couples with a broad consequence on their lives. This study investigated the effectiveness of laparoscopic surgery for treating infertility in Cameroon.

Methods: We conducted a cross-sectional, analytic study in order to determine the rate of conception and associated factors following laparoscopic surgery in women who presented with infertility, and treated at the Yaoundé

Gynaeco-Obstetric and Pediatric Hospital from January 1st 2007 to December 31st 2017.

Results: The average age of the included patients was $32.2 \pm 4.9$ years old. Married women and those with tertiary level studies were the most represented. The average duration of infertility stood at $4.6 \pm 2.8$ years. The most common surgical procedures were adhesiolysis ( $86.1 \%)$ and neo-salpingotomy $(55.4 \%)$. The conception rate after the endoscopic surgery was $39.3 \%(119 / 303)$. The associated factors were normal body mass index and the antecedent of two or more alive children.
\end{abstract}

Conclusions: The study revealed the efficiency of laparoscopic surgery in the management of infertility.

Keywords: conception rate; Infertility; Laparoscopic surgery; Yaoundé 


\section{Plain English summary}

Most of the time, conception is perceived as a happy event. However, due to some conditions, certain women are not able to get pregnant. Women infertility has many consequences and there are many affected women. Laparoscopic surgery is a means of treating women's infertility in some cases. In this study, we investigated the effectiveness of Laparoscopic surgery for treating women infertility, by estimating the conception rate following laparoscopic surgery in a reference hospital in Cameroon. The associated factors to conception following laparoscopic surgery for treating women infertility were also determined.

Data were observed retrospectively from registries of the Gynecology and Pediatric unit of the hospital. The inclusion criteria was women treated from infertility by laparoscopic surgery from 1st 2007 to December 31st 2017. Phone call interviews were also made to check the conception event and other information missing in the registries.

A total of 303 women was interviewed, 119 got pregnant following laparoscopic surgery, leading to a conception rate of $39.3 \%$. The associated factors were normal body mass index and the antecedent of two or more alive children.

In conclusion, laparoscopic surgery could be an important means for treating women's infertility and it should be pursued.

\section{Background}

Couple infertility is defined by the World Health Organization (WHO) as the absence of pregnancy in a couple of childbearing age following 12 to 24 months of unprotected intercourse[1]. Infertility can be primary or secondary. As a condition, infertility has complex moral repercussions on the individual, the family and society. It particularly could affect the dynamics of couple life, especially in a setting like ours where procreation is one of the main goals of marriage. In fact, it is one of the main causes of divorce in some countries such as Morocco and Algeria[2]. In line with its consequences on the life of the couple, it could lead to anxiety, depression, isolation, sexual problems, marital conflict, and low self-esteem [3]. Laparoscopic surgery constitutes one of the methods used to manage infertility. It permits direct visualisation of the abdominal cavity following abdominal cavity distension (pneumoperitoneum) by means of an endoscope introduced through the abdominal wall (laparoscopy or peritoneoscopy) or through the posterior vaginal fornix (trans-vaginal laparoscopy). As a minimally invasive surgical technique, it enables diagnosis and intervention within the abdominal cavity. The procedure which is performed under general anaesthesia, involves performing a small incision beneath the umbilicus, followed by insufflation of carbon dioxide into the abdominal cavity, as well as the insertion of a trocar across the same incision. In Cameroon, Gynaecological laparoscopy has been practiced for more than fifteen years[4]. Our goal was to determine the rate of and factors associated with spontaneous conception following laparoscopic surgery indicated in the management of couple infertility at the Yaoundé Gynaeco-Obstetric and Paediatric Hospital. 


\section{Methods}

This was a cross-sectional study which evaluated the conception rate and the associated factors after laparoscopic surgery at the Gynaeco-Obstetric and Paediatric Hospital of Yaoundé. The study was conducted over a 10-month period and included women who underwent laparoscopic surgery from January 1st 2007 to December 31st 2017. The minimum sample size calculated using the Cochrane formula[5] was 288 patients. Data were analyzed using $\mathrm{R}$ software version 4.0.2[6]. The threshold of significance was set at $5 \%$. The study participants were interviewed and examined for variables such as age, educational level, and the type of infertility, duration of infertility, gynaecological history and surgical indications. An experienced gynaecologist performed the surgeries at the surgical unit of the Yaoundé GynaecoObstetric and Paediatric Hospital. During laparoscopy, exploration of the pelvic cavity permitted evaluation of the uterus, fallopian tubes, and the pouch of Douglas. Furthermore, exploration of the abdominal cavity and especially the hepatic region permitted us evaluate the patients for peri-hepatic adhesions (peri-hepatitis), and a colorimetric test with methylene blue was also performed.

\section{Results}

A total of 504 patients underwent endoscopic surgery during our study period from which we included 303 patients in our study, which is a rate of participation of $60.12 \%$. The balance of 201 women was not either reachable for interviews or was not consent. The socio-demographic characteristics, clinical characteristics, surgical data, surgical procedures and the outcome of the pregnancy are represented in the tables 1, 2, 3, 4, 5and 6 respectively. From the 303 patients, a total of 119 got pregnant, that is a conception rate of $39.3 \%$. The table 6 provides the associated factors to the conception following laparoscopic surgery.

\section{Discussions}

The estimated conception rate in our cohort was $39.3 \%$ comparable to findings by other authors. Amongst them, [7] described rates of 38.5\% while [8] reported at $39.1 \%$. Also, [9] in Canada found a post-laparoscopy conception rate of $41 \%$ in 2006 , with [10] reporting a rate of $44.4 \%$ in Tunisia in 2012. The obtained estimated conception rate in this study was higher than findings by [11] in Cameroon, which was $27.3 \%$. This could be justified by the fact that [11] took into account just fimbrioplasty and neo-salpingotomy. The majority of patients had intrauterine pregnancies in $36.3 \%$ of cases, $1.0 \%$ of patients had ectopic pregnancies while patients with both extra and intrauterine pregnancies represented $2.3 \%$ of those who conceived following laparoscopy. The course of achieved intrauterine pregnancies was distributed as follows: $33.3 \%$ of live born children, $7.6 \%$ of spontaneous abortions, $4.3 \%$ had ongoing pregnancy at the time of the study, $1 \%$ lost their live born child. Our study also found out that $57.14 \%$ had a pregnancy within the first twelve months following surgery. That is similar to the result obtained by [12], where the average time of conception was between 4-9 months, with [13] in 2007 in France further reporting that $65 \%$ of patients got pregnant in the first eight months after endoscopic surgery. Also [14] found that most of the patients at $76 \%$ had an intrauterine pregnancy within 12 months or less, and that amongst the patients 
who got pregnant, $19.8 \%$ had at least two pregnancies after endoscopic surgery. The slight difference in percentage of conception within first twelve months following endoscopic surgery could be explained by the delay in treating infertility by laparoscopy surgery in most developing countries in general. After logistic regression, the factors that were significantly associated to conception after laparoscopic surgery included: An normal body mass index $[\mathrm{OR}=2.36(\mathrm{CI}=1.17-4.84) \mathrm{P}=$ 0.017 ] and an number of living children greater than or equal to $2[\mathrm{OR}=2.16$ (CI $=1.03-4.60) \mathrm{P}=0.04]$. A normal body mass index increased by two-fold a patient's chances of getting pregnant compared to the higher body mass index. A study conducted by [15] in France showed that body mass index is an important prognostic factor in a woman's fertility. Obese women with infertility need to adopt healthy lifestyle and dietary modifications towards improving their chances of conception. Women who had a history of at least two living children were also twice as likely to get pregnant compared to those with less. This could be explained by their greater fertility potential compared to the other women.

\section{Conclusions}

The estimated rate of conception after laparoscopic surgery at the Yaoundé Gynaeco-Obstetric and Paediatric Hospital was 39.3\%. The main associated factors were a normal body mass index and a history of at least two living children. The laparoscopic surgery is an important means for the treatment of women infertility, it should be therefore made accessible for a larger broad of the population. However, women suffering from infertility should adopt an adequate and healthy lifestyle(fitness, dietary and wellbeing practices) for normal body weight for the purpose of improving their chance of getting pregnant.

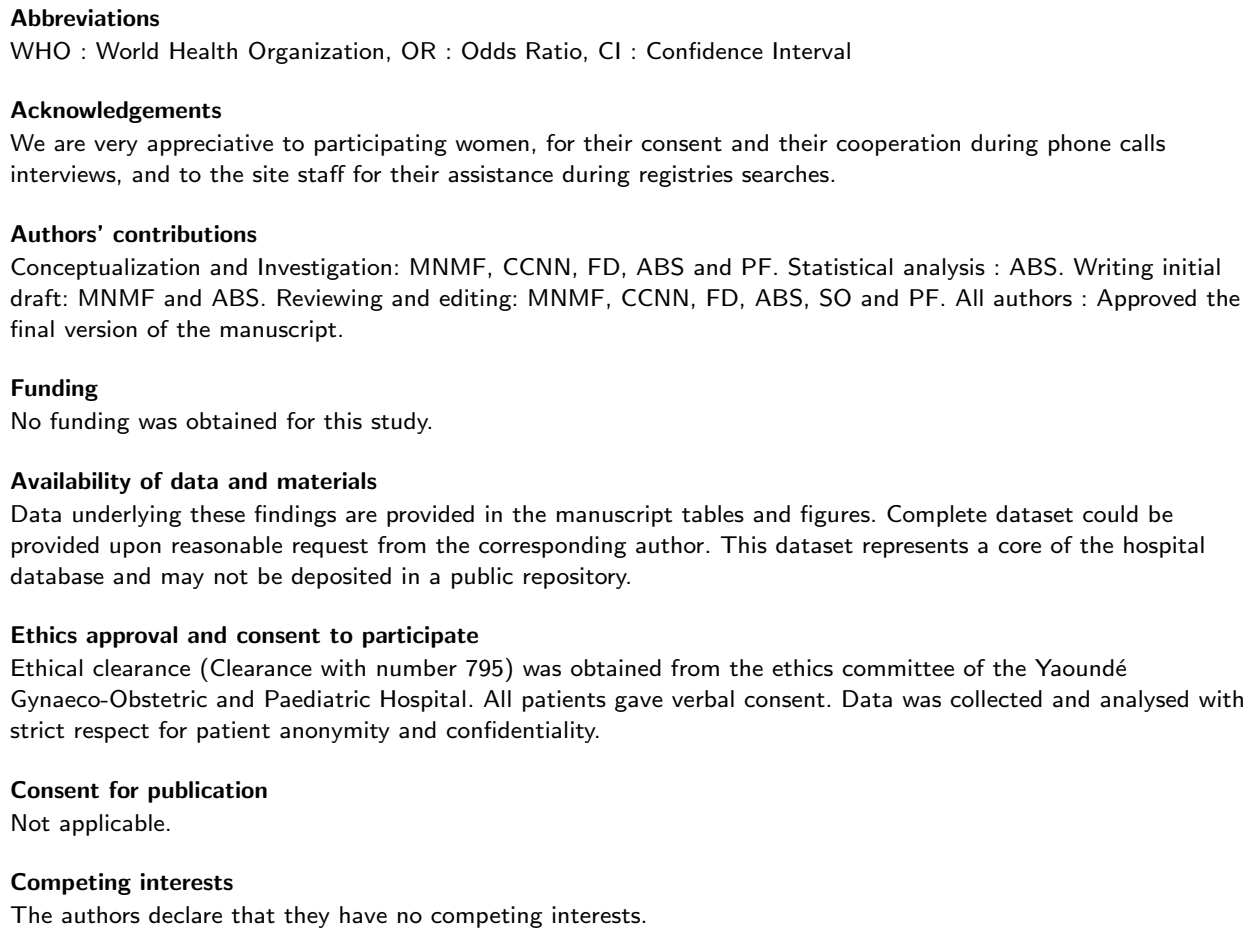




\section{Author details}

${ }^{1}$ Faculty of Health Sciences, Université des Montagnes, Baganté, Cameroon. ${ }^{2}$ Hospital Center for Research and Application in Endoscopic Surgery and Human Reproduction, Yaoundé, Cameroon. ${ }^{3}$ Faculty of Health Sciences, Université des Montagnes, Baganté, Cameroon. ${ }^{4}$ Department of Statistics and Actuarial Sciences, Jomo Kenyatta University of Agriculture and Technology (JKUAT), Nairobi, Kenya. ${ }^{5}$ Faculty of Medicine and Biomedical Sciences, University of Yaoundé 1, Yaoundé, Cameroon. ${ }^{6}$ Yaoundé Gynaeco-Obstetric and Pediatric Hospital, Yaoundé,

Cameroun.

\section{References}

1. Brzakowski M, Lourdel E, Cabry R, Oliéric M, Claeys C, Devaux A, et al. Épidémiologie du couple infertile. J Gynecol Obstet Biol Reprod. 2009;.

2. Hajjami HE. Infertilité masculine : profil épidémiologique et clinique. Université Sidi Mohamed Ben Ahdellah; 2017. Thèse de doctorat en médecine.

3. 1 couple sur 8 souffre d'infertilité au Maroc: Les femmes premières accusées;. Accessed: 01 June 2019. Available from: http://aujourdhui.ma/societe/ 1-couple-sur-8-souffre-dinfertilite-au-maroc-les-femmes-premieres-accusees-119304

4. Nzintcheu J, Foumane P, Mboudou E, Nana P, Foumulou J, Doh A. Périhépatite de découverte percoelioscopique pour infertilité à l'Hôpital Gynéco-Obstétrique et Pédiatrique de Yaoundé : Prévalence et corrélation avec les lésions tubo-pelviennes. Clinic Mother Health. 2012;

5. Lenth RV. Some Pratical Guidelines for Effective Sample Size Determination. The American Statistician. 2001;

6. R Core Team. R: A Language and Environment for Statistical Computing. Vienna, Austria; 2020. Available from: https: //www.R-project.org/.

7. Fongang JJ. Infertilité tubaire : Apport diagnostique et thérapeutique de la cœlioscopie dans le service de chirurgie ; $A_{i}$ du point $G$. Université de sciences, des techniques, et de technologies de Bamako; 2013. Thèse de doctorat en médecine.

8. Coulibaly S. Apport de la coeliochirurgie dans les affections gynécologiques bénignes dans le service de $i A_{i}$ au CHU du point G. Université de Bamako Faculté de Médécine de Pharmacie et d'Odonto-Stomatologie; 2007. Thèse de doctorat en médecine.

9. Taylor R, Berkouwitz J. Role of laparoscopic salpingostomy in the treatment of hydrosalpinx. Fertility and Sterility. 2001;

10. Rachdi S, Mesaudi F, Ben M, Basly M, Chlayh M. Apport de la coelioscopie dans la prise en charge stérilité tubaire. Afr J Reprod Health. 2012;

11. Kasia J, Ngowa J, Mimboe Y, Toukam M, Ngasssam A, Noa C. A Laparoscopic Fibrioplasty and Neosalpingostomy in female Infertilily : A Review of 402 Cases at the Gynecological Endoscopic Surgery and Human Reproductive Teaching Hospital in Yaoundé-Cameroon. J Reprod Infertil. 2016; .

12. Kauter D, Anissa G, Mohamed C, Ezzeddine S, Dalenda C. Résultats de la plastie tubaire : étude tunisienne. Pan Afr Med J. 2014;

13. Fuchs $F$, Raynal $P$, Salama $S$, Guillot $E$, Tohic L, Chis $P$. Fertilité après chirurgie coelioscopique de l'endométriose pelvienne chez des patientes en échec de grossesse. J Obstet Gynecol Reprod Biol. 2007;.

14. Filippini F, Darai E, Benifla J, Renolleau C, Sebban E, Vlastos G. Distal tubal surgery : A critical review of 104 laparoscopic distal tuboplasty. J Obstet Gynecol Reprod Biol. 1996;

15. Vincentelli C, Gaborit B, Castera V, Dutour A, Courbiere B. Courbiere B. Prise en charge de l'infertilité chez la femme obèse. Obésité. 2017;

Tables

Table 1 Distribution of the patients by socio-demographic characteristics Variables

\begin{tabular}{lcc}
\hline Variables & Sample sizes $(\mathbf{N}=\mathbf{3 0 3})$ & $\mathbf{\%}$ \\
\hline Age group (years) & & \\
{$[15-20[$} & 1 & 0.3 \\
{$[20-25[$} & 16 & 5.2 \\
{$[25-30[$} & 71 & 23.4 \\
{$[30-35[$} & 119 & 39.2 \\
{$[35-40[$} & 75 & 24.7 \\
{$[40-45[$} & 16 & 5.2 \\
{$[45-50[$} & 5 & 1.6 \\
Educational level & 184 & 60.7 \\
Higher & 112 & 37.0 \\
Secondary & 7 & 2.3 \\
Primary & 0 & 0 \\
Non schooling & & \\
Matrimonial status & 228 & 75.2 \\
Married & 75 & 24.7 \\
Single & & \\
\hline
\end{tabular}


Table 2 Distribution of the patients according to the type and duration of infertility

\begin{tabular}{lcc}
\hline Variables & Sample sizes $(\mathbf{N}=\mathbf{3 0 3})$ & $\%$ \\
\hline Infertility type & & \\
Secondary infertility & 213 & 70.3 \\
Primary infertility & 90 & 29.7 \\
Infertility duration & & \\
$\leq 2$ years & 72 & 23.7 \\
$>2$ years & 231 & 76.2 \\
\hline
\end{tabular}

Table 3 Distribution of patients by type of laparoscopic finding

\begin{tabular}{lcc}
\hline Laparoscopy findings & Sample sizes $(\mathbf{N = 3 0 3 )}$ & $\mathbf{\%}$ \\
\hline Pelvic adhesions & 266 & 90.2 \\
Adhesive trunks & 231 & 78.3 \\
fibromyomatous uterus & 89 & 30.2 \\
Ovarian cyst & 86 & 29.2 \\
Phimosis & 76 & 25.8 \\
Ovarian adhesions & 36 & 11.9 \\
Endometriosis & 27 & 9.2 \\
Peri-hepatitis & 27 & 8.9 \\
\hline
\end{tabular}

Table 4 Distribution of patients by surgical procedures

\begin{tabular}{lcc}
\hline Procedures made & Sample sizes $\mathbf{( N = 2 9 5 )}$ & \% \\
\hline Adhesiolysis & 261 & 86.1 \\
Neo-salpingotomy & 168 & 55.4 \\
Endometriosis Coagulation & 14 & 4.6 \\
Ovarian Drilling & 20 & 6.6 \\
Fimbrioplasty & 71 & 23.4 \\
Cystectomy & 63 & 20.8 \\
Myomectomy & 48 & 15.8 \\
\hline
\end{tabular}

Table 5 Distribution of patients by outcome of achieved pregnancy

\begin{tabular}{lcc}
\hline Pregnancy and its becoming & Sample sizes $(\mathbf{N = 1 1 9})$ & $\mathbf{\%}$ \\
\hline Intra-uterine pregnancy & 109 & 36.3 \\
Live baby & 100 & 33.3 \\
Spontaneous abortion & 23 & 7.6 \\
Pregnancy in progress & 13 & 4.3 \\
Intra-uterine foetal demise & 3 & 1.0 \\
Other pregnancy outcomes & 7 & 2.3 \\
Ectopic and intrauterine pregnancies & 7 & 2.3 \\
Ectopic gestations & 3 & 1.0 \\
\hline
\end{tabular}

Table 6 Factors associated with conception following laparoscopic surgery

\begin{tabular}{lcc}
\hline Variables & Adjusted OR (95\% CI) & P-value \\
\hline Two or more alive children & $4,60(1,36-17,3)$ & 0,010 \\
Normal Body mass Index & $2,36(1,17-4,84)$ & 0,017 \\
\hline
\end{tabular}

